\title{
A Case Study on Climate Change Response and Adaptation: Fictional Aysese Islands in the South Pacific
}

\author{
Amy Cannon', Peter Lalor ${ }^{2}$, Shobha Sriharan³, Chunlei Fan4, Gulnihal Ozbay ${ }^{*}$ \\ ${ }^{1}$ Department of Agriculture and Natural Resources, Delaware State University, Dover, DE, USA \\ ${ }^{2}$ University of the Sunshine Coast, Sunshine Coast, Queensland, Australia \\ ${ }^{3}$ School of Agriculture, Virginia State University, Petersburg, VA, USA \\ ${ }^{4}$ School of Computer, Mathematical and Natural Sciences, Morgan State University, Baltimore, MD, USA \\ Email: accannon10@students.desu.edu, pll002@student.usc.edu.au, Sriharan@vsu.edu, \\ Chunlei.fan@morgan.edu, ${ }^{*}$ gozbay@desu.edu
}

Received 18 October 2014; revised 15 November 2014; accepted 11 December 2014

Copyright (C) 2014 by authors and Scientific Research Publishing Inc.

This work is licensed under the Creative Commons Attribution International License (CC BY).

http://creativecommons.org/licenses/by/4.0/

(c) (i) Open Access

\begin{abstract}
The Intergovernmental Panel on Climate Change (IPCC), established by the United Nations and World Meteorological Organization, has determined that humans have very likely influenced a net warming to the Earth from the increase of greenhouse gases, aerosols and land use changes. This warming has caused the amount of ice on the Earth to continue to decrease and sea levels to rise. In addition, extreme precipitation events are happening more often in selected regions of the world. A case study that assesses the impacts of, and adaptations to, these changes in climate is presented here. Two modeling programs, Sim CLIM and Train CLIM, (CLIM Systems, Hamilton, New Zealand) were used to support assessments for water supply, coastal zones and tropical cyclones in a fictitious island group in the South Pacific region. In the case study, a consulting group was "hired" to carry out these assessments. A final analysis and synthesis report were created to help the Ministry of the Environment of the made-up nation decide how to improve the governmental actions to address the real concerns posed by changing climate and sea level. Although a simulated island group is used in this article, there are sincere concerns about climate change and extreme weather events in this part of the world. It is important to address the real and dangerous threat that these islands and people face in the wake of a changing climate and a growing global society.
\end{abstract}

\section{Keywords}

Climate Change, Case Study, Water Supply, Coastal Zone Erosion, Tropical Cyclones

\footnotetext{
${ }^{*}$ Corresponding author.
} 


\section{Introduction}

The Climate Change and Adaptation Group was divided into consulting firms during the summer learning opportunity at the University Sunshine Coast, Queensland, Australia. Each firm was challenged to use the most upto-date software to provide recommendations to the Ministry of the Environment of the Aysese Islands for how to face the changing climate. This was done in order to save lives, save money, and prevent home loss for people on the island. The softwares used were the SIMCLim and Train Clim programs, created by CLIM Systems. They are also utilized by the United Nations in decision-making processes regarding climate change projections for the globe. There is other optional developing software that is used by other scientists that offer alternatives to the SIMCLim and TrainClim programs. The following information details the situations that are placed before us and our responses including how to best address the immediate concerns of the health and welfare of the people on these islands.

In reality, the Aysese Islands do not exist. However, the data provided here shows a close representation of the South Pacific Island region of the globe. Many people live in this area, and have to face these challenges in their daily lives. It is important that we look at this study as a means for how to address changing climates and our surroundings to provide logical plans for preserving the health and safety of all people. It also outlines how the changing climate is most likely the result of human actions ( $>90$ percent certainty) [1]. With this being held true, this article was being shared in the hopes of raising awareness and thoughtfulness in all people to help change the Earth back to the way it was meant to be, and to make changes that will benefit future generations.

This synthesis is based on the assessments of our consulting firm, and considers many of the factors affecting the Aysese Islands. It provides an integrated view of the region with consideration to global impacts of climate change in each sector that has been reviewed.

The firm has provided reporting on the drivers and risks found in the Aysese Islands, as well as how these sectors are affected by climate change. We first address the baseline drivers of change and risks in the region in relation to socio-economic factors. We then assess how climate change affects each factor and how they are all interconnected. Finally, we address specific issues of concern in relation to water resources, coastal erosion, and tropical cyclones with storm surge flooding, respectively.

The schematic framework in Figure 1(a) shows these drivers, risks, and climate change scenarios as well as their connections to one another. The diagram is examined in this report from the foundation of the links between natural systems and how the impacts of these systems affect human systems in the Aysese Islands region, specifically.

In each section, recommendations have been made to address the natural systems, then the drivers of change in these systems. Next, we assess the impacts and vulnerabilities of each system and how these fit into the human systems within the local region.

Climate change has been considered by the Intergovernmental Panel on Climate Change (IPCC), and many other organizations, and has been defined as a relevant concern for the entire globe. This assessment considers climate change as an important factor in all determinations. Throughout the careful assessment, an attempt is made to reinforce the necessity to understand the interconnectedness of natural and human systems, the fragility of the relationship between the two, and the sensitivity this relationship has to climate change [2].

Adaptations must be made in the way in which the region is currently developing. Aysese Islands must prepare for the changes that are occurring so that it is well adapted to the future. Both natural and human systems will be affected by the changes that are projected to occur. These projections are made with the most modern modeling software, and examined and double-checked.

The most important message contained within this report can be encapsulated in a few words. The Aysese Islands, in the context of the entire globe, are in a particularly vulnerable geographic location that is susceptible to the changes in climate and must make preparations for future changes to continue growth and economic development.

\section{Case Description}

\subsection{Overview of the Republic of Aysese Islands}

As an overview of the Republic of Aysese Islands, the nation is a small island state located in the South Pacific Ocean region at $5^{\circ} \mathrm{N}$ latitude and $165^{\circ} \mathrm{E}$ longitude. The culture of this nation is set up in tribal groups and rural 


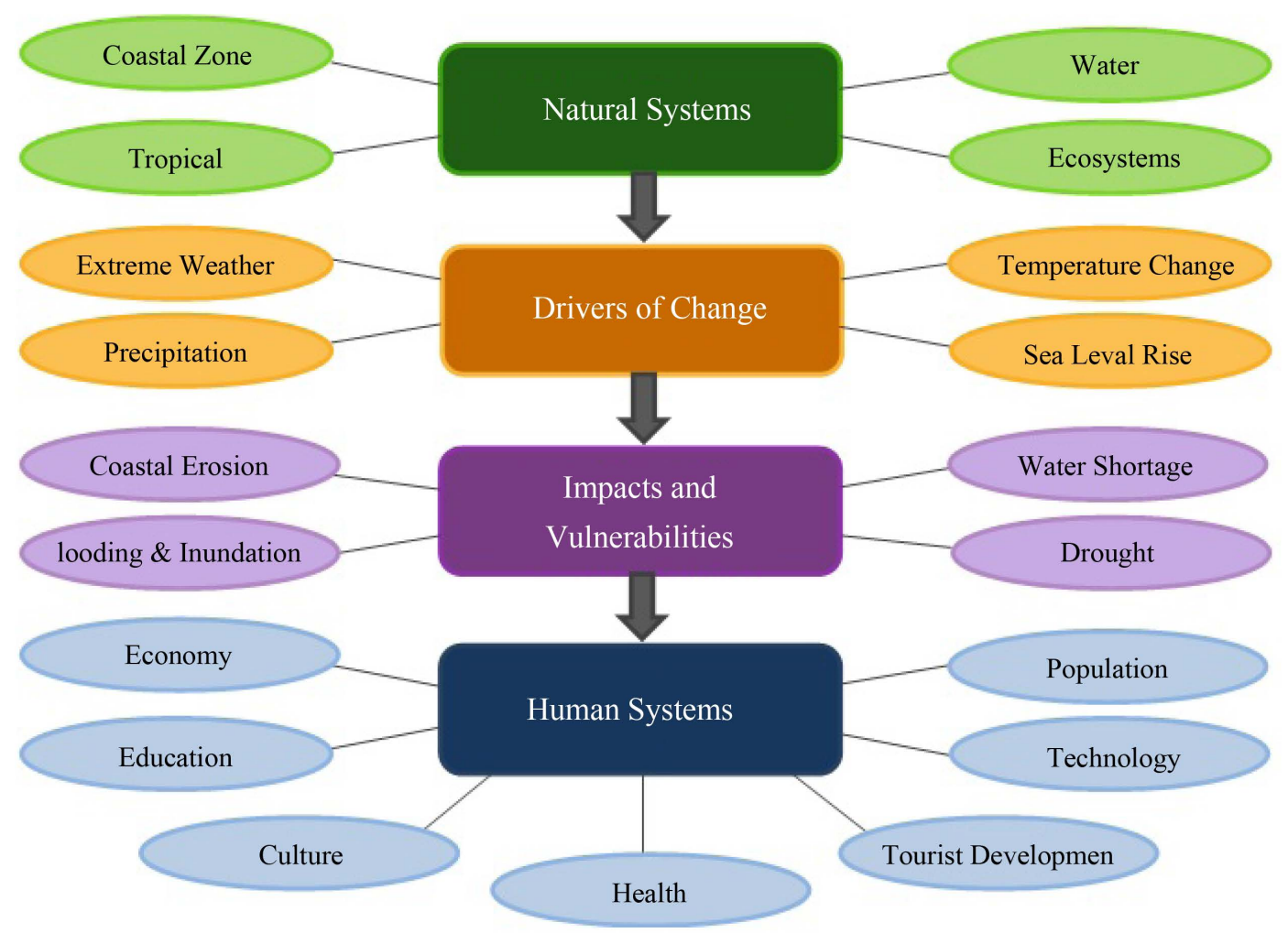

(a)

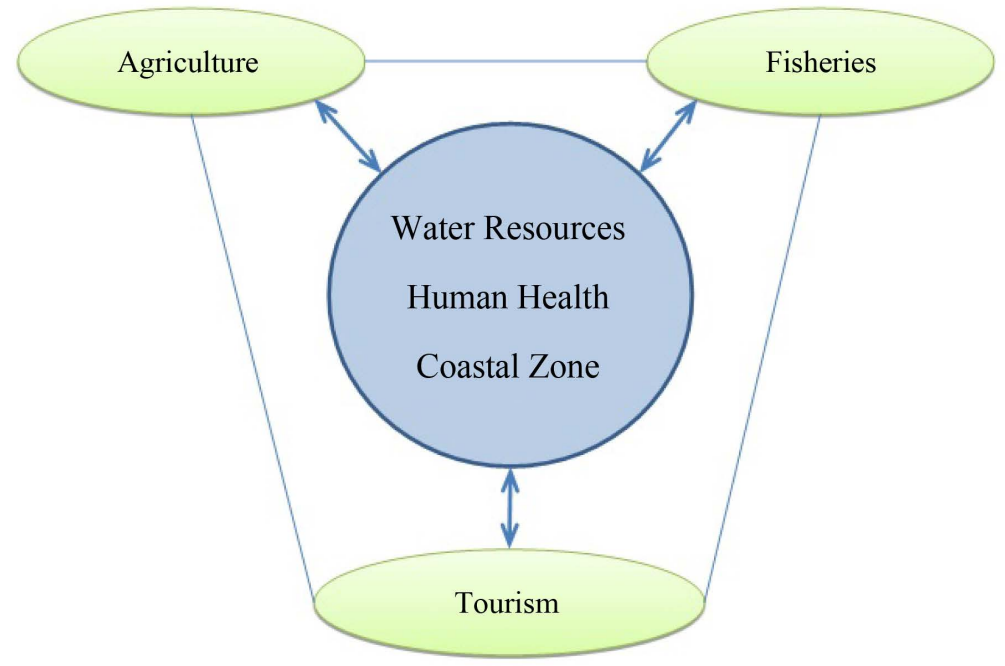

(b)

Figure 1. (a) Schematic framework representing foundation of natural systems and their relation to human systems in Aysese Islands in South Pacific; (b) Visual representation of the recommendations and connectedness of three most important sectors.

settlements are predominant, while some areas are slowly developing into towns. Females have a lower literacy rate than males. Some informal settlements have developed on the outskirts of towns due to inability to make a profit from fishing. These areas show problems that are typical of poor areas of developing countries such as poverty, overcrowding, inadequate water supplies and sanitation, along with frequently polluted water supplies, unsanitary water storage facilities and a multitude of health problems. The economy is primarily sustained by agriculture and fishing. Tourism is also a growing industry as well. The environment on the Island consists of 
high mountainous elevations, down to coastal plains along the coasts. There are many animal species that are dependent on existing vegetation, and consideration should also be given to their survival in relation to climate change affecting the existing habitats. There are forests, as well as mangrove wetland coastal areas, coastal wetlands, and coastal terrestrial systems. In the surrounding waters of the island, there are coral reefs which provide habitat for juvenile fish and many other aquatic organisms. The climate found in Aysese Islands is tropical on the main volcanic island, with higher temperatures along the coastal areas, closer to the water. Lower temperatures occur in higher elevations, closer to the mountain peaks. Precipitation occurs more in the higher elevations, with less precipitation in the lower elevations. The north western part of the island receives less precipitation, as it is the leeward side of the mountain range. A rain shadow prevents this north-western area from receiving more precipitation than the rest of the island.

\subsection{Socio-Economic Drivers of Change}

The Aysese Islands is characterized as having a population that predominantly resides on the coastal lowlands. Coastal lowlands exhibit an existing high vulnerability to the effects of tropical cyclones, including damage from high wind speeds, flooding and storm sea surges. Storm tracks to the north of the capital Amilee put it at particularly high risk. With a population growth rate of $2.2 \%$ per annum, the Aysese Islands population will double to 182,000 by 2044 . As the economy grows and it moves away from a strong reliance on agriculture and fishing and towards more skilled industry and services, the greatest population growth will happen in the already heavily-populated coastal towns, particularly the capital Amilee. Falulu (the large island) as a whole is experiencing an urban growth rate of $4.4 \%$. This will put a much greater proportion of the population at greater risk of tropical cyclones in future decades.

In terms of human health, the Aysese Islands is a nation with limited capacity to cope with outbreaks of disease and other health problems associated with climate change and variability. A high population growth rate will put greater pressure on the health system in the future.

Currently, the Aysese Islands relies very heavily on agricultural and fishing industries, contributing to almost half the total Gross Daily Product (GDP). These industries will be put under much stress in the future due to climate change. As a result of this coupled with a tendency toward development and modernization, it is likely that agriculture and fisheries will decline in the future as industries like tourism and other services increase. This increases vulnerability in two ways. Firstly, subsistence agriculture and fisheries play a large role in helping locals cope with disasters such as cyclones, as a sense of tradition ensures that everyone in an extended family and the community receives food and does not suffer. A second problem is faced if the agricultural and fishing industries are replaced with a greater reliance on the tourism industry. Tourism has provided most Pacific island nations with a strong income, as is the case with the Aysese Islands; however the industry is likely to be detrimentally affected by climate change in the future.

The Aysese Islands has an adult literacy rate of $83 \%$, slightly above the world average. While this figure is fair for a developing country, a lack of opportunity in high-paying jobs sees many skilled workers and professionals emigrating from the Islands to developed countries such as Australia and New Zealand. This human capital flight poses vulnerabilities in the future as it limits the amount of local people with the capacity to develop technology and work toward adapting to climate change, instead relying on aid workers and potentially expensive foreign workers and professionals.

\subsection{Existing Climatic Risks}

Existing climatic risks faced by the Aysese Islands are storm surges from precipitation events and tropical cyclones which threaten the livelihood of the nation's agriculture. High soil drainage that keeps soils from remaining moist without frequent precipitation poses a risk to natural vegetation as well as agricultural crops. Infrastructure being situated near coastal areas creates a hazard in relation to damaging storm events. A high erosion rate from deforestation endangers crop survival, as well as Aysese Islands' resident survival in the wake of potential landslides. This particular driver has been created by the inhabitants of the Island by prior logging of terrestrial forests to support the economy. Severe flooding can occur from storm surges and tropical cyclones, imperiling lives of residents and livelihood of farmers. Beach erosion from storms causes the coastline to move inland which can hamper crop growth. Coral bleaching from increases in water temperatures in La Nina periods 
leads to the destruction of the coral reefs surrounding Aysese Islands. The environmental science is complex in coral reefs and many species which have a symbiotic relationship within these systems may suffer as a result of changes in salinity, sediment loads, and turbidity. Eutrophication of coastal waters brings about loss of oxygen in these marine ecosystems, which in turn makes an environment that does not support aquatic life [3]. Population density is greatest along coastal areas, and as such creates an area of vulnerability when storm surges approach, for loss of life, and loss of morale and workforce if deaths occur due to large storm events. In addition, small changes in sea level can produce higher ground-water levels, which can in turn affect the ability to grow crops [4]. Potential loss of food sources, as well as economic income from agriculture is another area of exposure for this nation. Another climatic difficulty is that changing sea surface temperatures have the potential to change the patterns of currents and affect availability of nutrients in addition to migratory patterns of certain fish such as tuna. In addition, the sex ratio of turtles depends directly on medium temperatures, because higher temperatures will result in a higher female to male ratio.

\subsection{Vulnerability of Sectors}

The quality of the water supply sector is crucial to the well-being of Aysese Island's natural and human systems. The Islands are subject to El Niño-Southern Oscillation (ENSO) and as such receive dryer periods during the El Niño phase. Together with the dryer winter months of May to October and the effects of increased climate variability, this puts the Islands at moderate risk of drought. The La Niña phase of ENSO is associated with higher levels of precipitation, as are the summer months of November to April. Considering its typically high levels of precipitation, the Aysese Islands are highly vulnerable to flooding from storms and tropical cyclones.

Human health is another sector that naturally takes a high priority. It is highly vulnerable to storm surges and tropical cyclones, both of which can cause injury and death through flooding and high wind speeds. Another human health risk associated with storms and cyclones is the outbreak of diseases such as cholera through contaminated drinking water supply and disrupted sanitation services [5]. One such example given by Traerup et al. [6], by 2030 with a 1 degree Celsius increase in annual mean temperature, based on the model focusing on the relationship between cholera cases and temperature, we predict an increase in the initial risk ratio for cholera in Tanzania in the range of 23 to 51 percent in Tanzania. Human health is also moderately vulnerable to the effects of mean temperature rise, with a potentially greater rate of heat stroke, dengue fever, malaria and ciguatera fish poisoning [6].

The coastal zone is a particularly important sector to the Aysese Islands given its large coastal population. Coral reefs in the coastal zone face a high degree of vulnerability to temperature rise and sea level rise respectively, through bleaching and increased algal growth, respectively [3]. Costal zones are highly vulnerable to storm surges and subsequently erosion, as it threatens the infrastructure of coast-lying settlements.

The agricultural and forestry industries contribute to a large portion of the Aysesenese economy and share high vulnerabilities to potential drought and wind damage from tropical cyclones, each of which can destroy entire crops. Also, a moderate risk is posed by the effects of inundation from storm surges, mean temperature rise and sea level rise in the low-lying coastal regions.

Fisheries provide the Aysesenese people with income and subsistence, as well as being important to their traditional culture. It is, however, vulnerable to a number of risks. The industry is highly vulnerable to sea temperate change, as this affects the breeding processes of many species, changes the migratory patterns of some fish, promotes algal blooms, and disrupts the sensitive shallow waters and reefs [7]. A moderate risk is also posed by high rainfall events such as storms and cyclones, as this can lead to nutrient and sediment loading [4].

The rapidly growing tourism industry is vulnerable to many risks of climate vulnerability and change. Most hotels and resorts are located very near the coast, making the industry vulnerable to erosion and inundation from storm surge and sea level rise. Sea temperate rise also presents a high risk to tourism in the way of coral bleaching, which potentially can destroy the Island's most popular attractions. Temperature rise can also threaten tourism by the way of increasing outbreaks of diseases such as dengue fever, malaria, and ciguatera fish poisoning [6] (Table 1).

\subsection{Recommendations and Focuses for the National Vulnerability and Adaptation Assessment}

First, the priority sectors to be included in the Assessment will be Water Resource, Human Health, and the 
Table 1. Matrix displaying level of vulnerably of different sectors to common risks. That is, a visual representation of the risks that are faced in the Aysese Islands, as well as the different sectors that each risk may potentially affect. In addition, there is a Low to High ration that is shown here to address the possibility of each risk affecting each sector.

\begin{tabular}{cccccc}
\hline Sectors & Tropical & Storm Surges and & Drought & Temperature & Sea Level Rise $^{*}$ \\
\hline Change & Erosion & Low & Low \\
Huter Supply & High & High & Moderate & Moderate & Low \\
Coastal Zone & High & High & Low & High & High \\
Agriculture and Forestry & Low & High & Low & Moderate & Moderate \\
Fisheries & Hoderate & Moderate & Low & High & Low \\
Tourism & Low & High & Low & Moderate & High \\
\hline
\end{tabular}

${ }^{*}$ Two different projections for low, medium and high sea level rise risks by the year 2050 and 2100 are presented in Figures 4(b)-(c). Figure 4(b) shows site-specific projected sea level rise for the Amilee area using the HadCM3 model; Figure 4(c) shows site-specific projected sea level rise for the Amilee area using the CSIRO-MK2 model. Both models project the low risk for sea level rise by 2050 as $10 \mathrm{~cm}$ and by 2100 as $20-25 \mathrm{~cm}$. Medium and high risks projections yield much higher levels according to both models. Figure 4(d) shows a trend in shoreline change (m) based on an observed sea level rise of 1.5 millimeters per year. Figure 4(e) shows mean, low and high shoreline change (m) based on an observed sea level rise of 1.5 millimeters per year using the Monte Carlo simulation with a confidence interval of $95 \%$.

Coastal Zone. The rest of the sectors will be provided with the means to grow and thrive as long as these three main components are organized into healthy viable systems. Study areas will include using existing topographic information to follow water flow along the contours of the island. This will begin revitalization of the first sector of Water Resources. In this way, means for providing sanitary water can be assessed for residents. When sanitary water becomes regularly available to all residents, the Human Health sector of the Assessment will begin to improve. In addition to sanitary water for drinking and cleaning, it is crucial that infrastructure be created to maintain a water supply free of bacterial contamination. This will eliminate many of the diseases that are the leading causes of death in all age groups. Sustaining a healthier population will help this nation to move forward in growth and means of livelihood, economically and otherwise. Human Health can also be improved upon by providing education to the public. Education in the form of knowledge of how to avoid disease is adequate, but by improving the literacy rate of the nation, the knowledge base of the Aysese Islands will become such that it can grow and move forward in sustaining itself in whatever ways it so chooses. The final sector of concern is the Coastal Zone. Without the health of the Coastal Zone, the tourism industry will die away, and so will the livelihood of all people in the Aysese Islands. In order to evolve towards success in survival and growth, the Coastal Zone must be considered as a primary resource to be protected and nurtured in ways that do not cause economic hardship upon the nation. Time horizons should be calculated in 100 year increments. Considerations will be given to every 30 year mark, and progress will continue to be assessed as steps are made towards sustenance of this nation, and the ability to sustain itself is given to the power of the people. We will involve residents in all levels of assessment and implementation to ensure that success is met at every juncture. Figure 1(b) illustrates the three main sectors of concerns addressed in this report and the factors they most directly affect.

\subsection{Global Projections of Climate and Sea Level Changes}

Global climate is likely to rise in the range of $1.7^{\circ} \mathrm{C}-4.4^{\circ} \mathrm{C}$ by the end of the $21^{\text {st }}$ century [1]. The causes point to human activities from burning of fossil fuels, use of aerosols, and land surface changes as having a substantial warming influence on global climate [1]. Broad uncertainties of global climate increase are that information on past changes in the sun are not based upon direct measurement, and the influence that these changes have had in altering the balance of incoming and outgoing solar energy is difficult to determine without measurement of these physical changes [1]. Geographically, projected global temperature increases are shown to be greatest at high northern latitudes and over land, with less increase over the southern oceans and the North Atlantic Ocean [7]. See Figures 2(a)-(b) for two graphic representations of the expected increase in global temperature in ${ }^{\circ} \mathrm{C}$ by 2080. These are median projections, and do not by any means represent the worst case scenarios that are possible. They are shown in Figures 2(a)-(b).

Sea level change that might happen in the future is also a concern. On a global scale, "sea level is expected to rise between 9 and 90 centimeters by the end of the century, with the Pacific Ocean experiencing the largest rise 


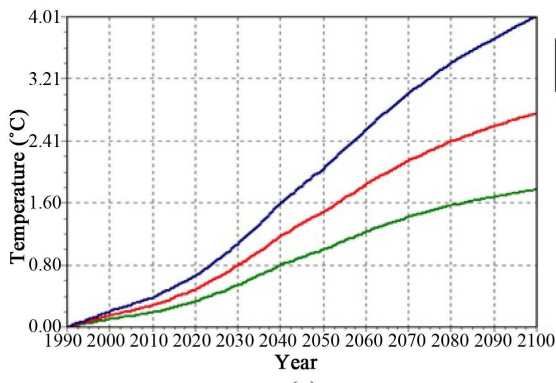

(a)

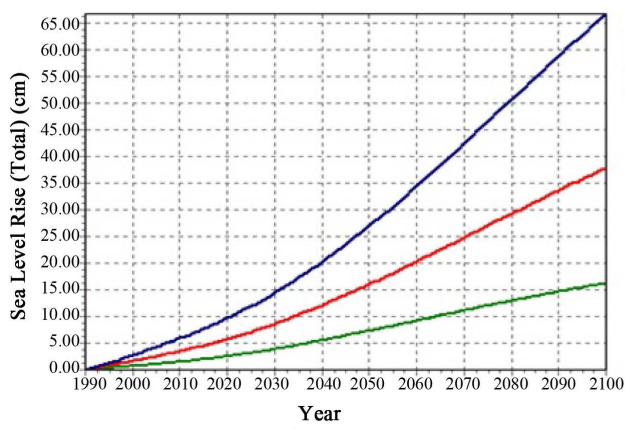

(c)

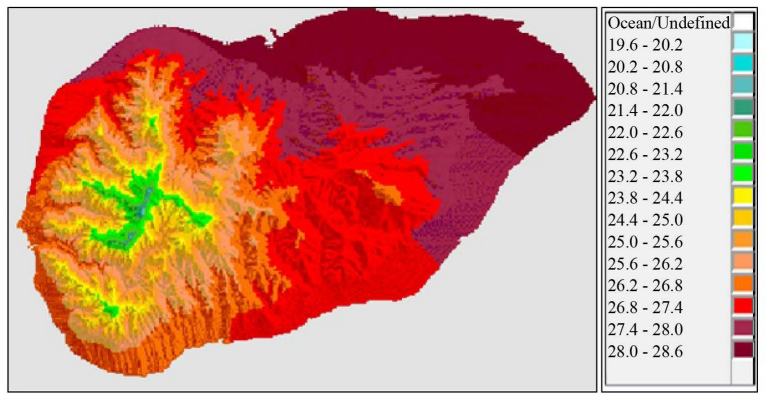

(e)

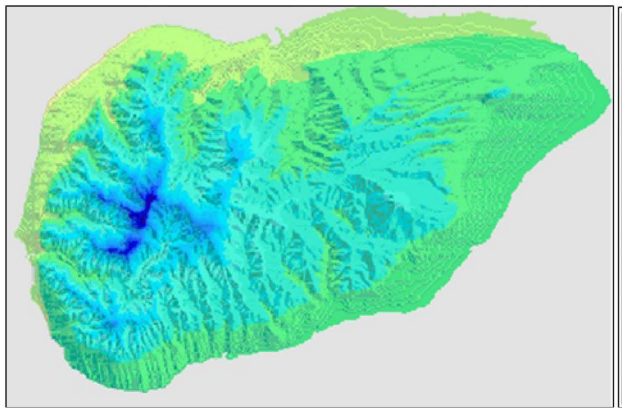

(g)

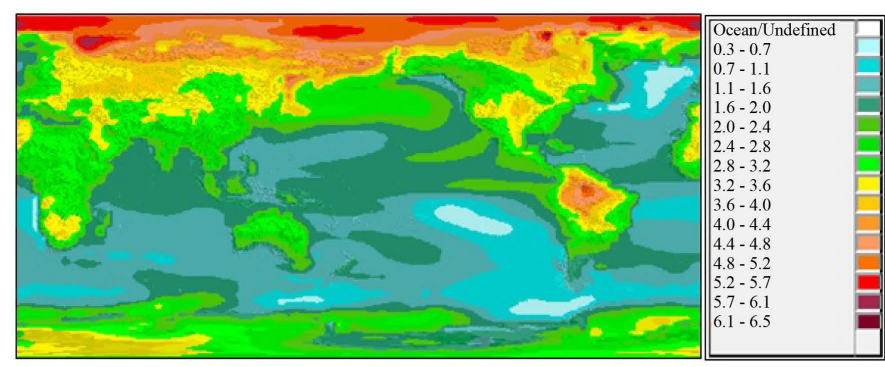

(b)

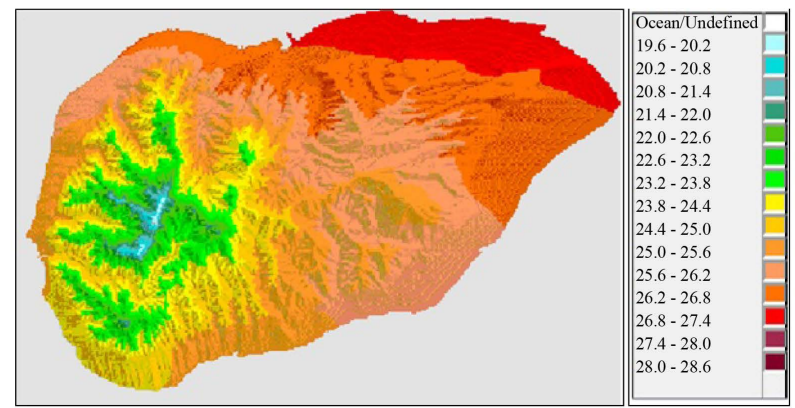

(d)

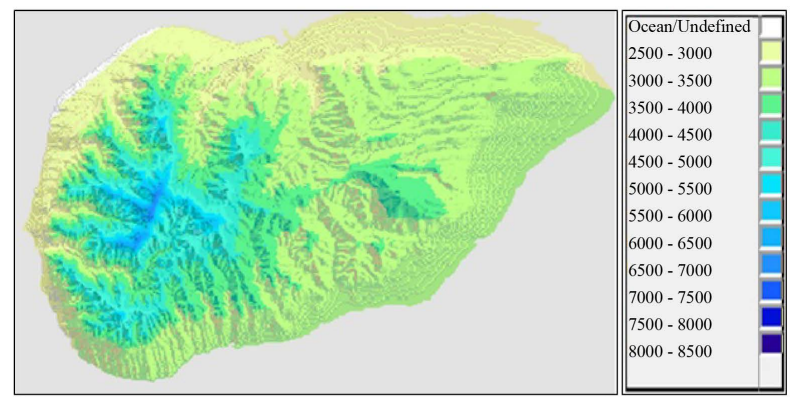

(f)

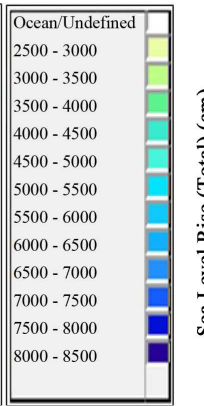

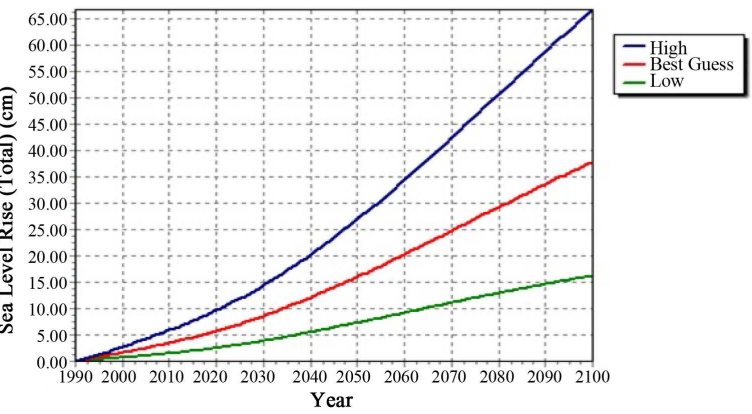

(h)

Figure 2. (a) Graph showing global-mean temperature changes $\left({ }^{\circ} \mathrm{C}\right)$; (b) Map showing global-mean temperature changes $\left({ }^{\circ} \mathrm{C}\right)$; (c) Global mean sea level rise $(\mathrm{cm})$; (d) Current mean temperatures $\left({ }^{\circ} \mathrm{C}\right)$ on Falulu; (e) Projected mean temperature $\left({ }^{\circ} \mathrm{C}\right)$ in 2080; (f) Current mean yearly precipitations (millimeters) on Falulu; (g) Projected mean yearly precipitation (millimeters) on Falulu; (h) Falulu Island sea level change (cm).

[8]”. Sea level will continue to rise because of thermal expansion, loss of land ice, loss of ice from ice sheets and emission of greenhouse gases [1]. The broad dilemmas in sea-level rise projections are that the levels of the rising are varied across modeled projections due to the inability of models to accurately project how much ice will melt in what period of time [1]. Globally projected patterns of change to sea levels are not geographically uniform [1]. Please see Figures 2(a)-(b) for graphics on how sea level rise is expected to change going forward into 
the future. In Figure 2(c), you will find medium levels of projected sea-level rise that do not approach the strongest possibilities.

\subsection{Possible Spatial Changes in Climate and Sea Level for the Island of Talufu}

Compared to current patterns of temperature and precipitation, the future holds many changes in store for Falulu. When considering temperature, it becomes clear in the maps in Figures 2(d)-(e) that temperatures are expected to rise.

In relation to precipitation, the rate is also expected to increase, based on the background information provided by Griffiths et al. [9] on the rainfall and precipitation projection data across the south pacific. Please see Figures 2(f)-(g) to explore a visual representation of the projected changes in precipitation rates moving forward into the future.

By observing the expected changes, one can begin to understand that these increases must be addressed. The range of uncertainty is difficult to determine due to the fact that exact measurements provided do not have a statistical standard deviation. What can be determined is that the SRES A1B (Special Report on Emissions Scenarios, A balanced emphasis on all energy sources, see List of Abbreviations for further details) emission scenario has been used to answer the questions asked about changes in temperature, precipitation and sea-level rise in this assessment. The A1B scenario assumes a balance between fossil fuels energy sources and similar improvement rates apply to all energy supplies and technologies [10].

A leading cause for concern is illustrated in Figure 2(h). The concern is that the island states of the Caribbean and the Indian and Pacific oceans are particularly vulnerable to increased flooding as a result of sea levels rising and increased precipitation [11]. Considering the information above in regards to precipitation and the information below in regards to sea-level rise, it is imperative that we consider climate change real indeed, and begin to address the concerns that changes in climate will bring. Climate change will exacerbate current climate related risks in the Pacific Island area. The key concern is the likely increased frequency and severity of an extreme event, rather than the more gradual change in the average climate. Every effort must be made to ensure adaptation thresholds are not surpassed. Risk management of natural hazards could significantly reduce the magnitude of future disasters [8].

\subsection{Conclusions on Climate Change}

Empirical evidence shows that globally, and indeed the Aysese Islands, climate change is being experienced. Even with a modest increase in temperate that has been used in modeling these climate change scenarios, we see a significant increase in the risks associated with temperature rise, droughts, tropical cyclones, storm surges and sea level rise [1].

\section{Discussion and Evaluation}

\subsection{Water Resources}

At present, the town of Amilee is entirely reliant on the Lao Pao River for its water supply. Even though the area enjoys a fairly consistent level of precipitation, the limited capacity of the water storage facility coupled with the requirement of a limited stream flow places the town at risk of water shortage during the dryer months. This section will assess the risk of water shortage under baseline conditions in addition to assessing risks under the conditions of climate change. Recommendations will then be made as to the steps the Government should make in order to reduce the risk in the future. Figure 3 shows current water demand.

\subsection{Present Risks of Water Shortage under Current Climate and Current Water Demand}

As seen in Figure 3, the current return period for water shortage is 13.09 years. This means that the city would run out of water approximately once in every 13 years. This risk is unacceptable according to the terms of current government policy, which requires that the acceptable risk is the occurrence happening once in every 25 years, not once in every 13 years. This information is a baseline of current usage as of today, with no increased usage demand, and no climate change considered. This is the opposite of Table 2 that shows multiple scenarios with and without climate change. CGCM2 scenario is generated by data from Meteorological Research Institute in Japan (see List of Abbreviations for further details). 
Table 2. Synthesis of all data presented below in report format of increased demands to storage and climate change adaptations considered.

\begin{tabular}{|c|c|c|c|}
\hline \multicolumn{4}{|c|}{ Future Water Shortage Risks } \\
\hline Model Run & & & Indicators of Impact or Risk \\
\hline Impact Assessment & $\begin{array}{l}\text { Socio-economic } \\
\text { (adaptation level) }\end{array}$ & $\begin{array}{l}\text { Climatic Change } \\
\text { (scenario) }\end{array}$ & \\
\hline $\begin{array}{l}\text { Climate change only, } \\
\text { demand constant }\end{array}$ & 14-day storage & Year 2075, using CGCM2 & Return period $=8.79$ \\
\hline $\begin{array}{l}\text { Increased demand, no } \\
\text { climate change }\end{array}$ & 7-day storage & Current climate & Return period $=8.15$ \\
\hline $\begin{array}{l}\text { Increased demand, } \\
\text { with climate change }\end{array}$ & 7-day storage & Year 2075 CGCM2 & Return period = 5.62 \\
\hline
\end{tabular}

Adaptation: Increase storage (compare with Runs 1 and 4 above to assess relative effects of adaptation options)

Level of adaptation (increased storage) required to meet current risk policy

Level of adaptation (increased storage) to future risks from rising demand without climate change

Level of adaptation (increased storage) to future risks, with climate change and rising demand

Days of storage beyond 14 needed to reach 1-in-25 year return period

Current climate

Additional storage days $=11$ Return period change: From: 1-in 13

To: 1 -in-25

Additional Storage required: $38,720 \mathrm{~m}^{3}$

Additional storage days $=18$ Return period change:

Days of storage beyond 7 needed to reach 1-in-25 year return period

Current climate

From: 1 -in-8

To: 1 -in-25

Additional storage require:

$63,360 \mathrm{~m}^{3}$

Additional storage days $=24$ Return period change:

Days of storage beyond 7 needed to reach a 1-in-25 year return period

Year 2075 CGCM2

From: $1-$ in-6

To: 1-in-25

Additional storage required

Days of storage beyond 7 needed to reach a 1-in-25 year return period
Additional storage AVOIDED:

Year 2075 CGCM2 $36403.64 \mathrm{~m}^{3}$ having to provide its own water supply, aside from residents

Level of adaptation (increased storage) to future risks, with climate change and rising

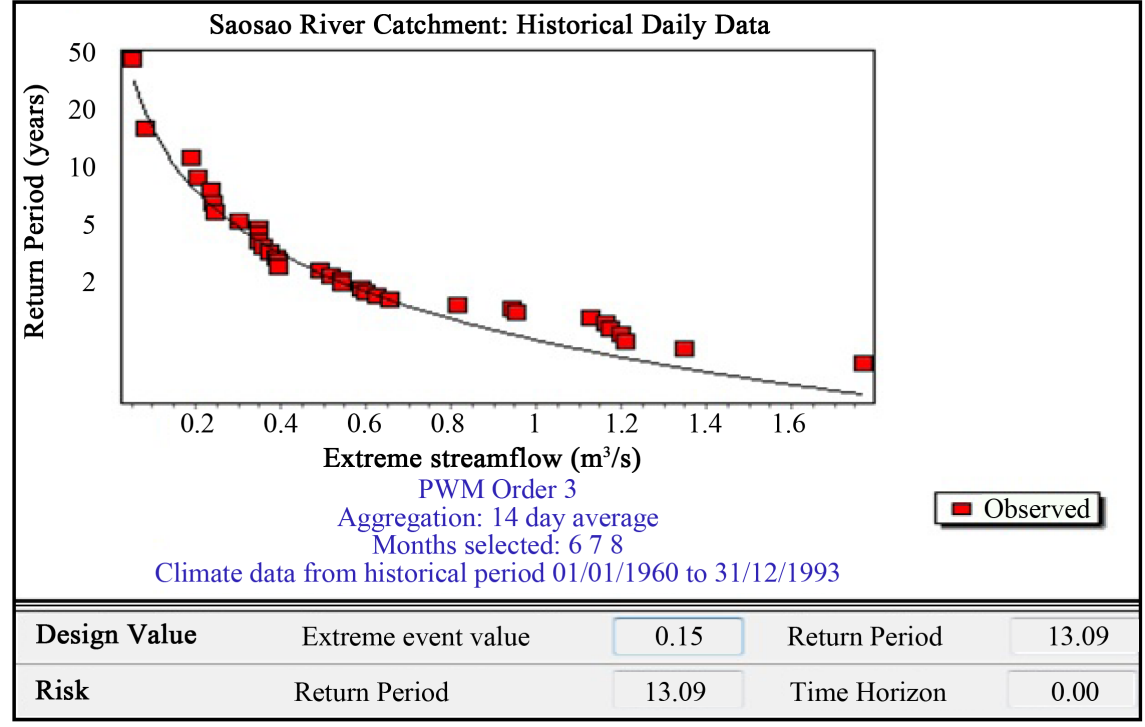

Figure 3. Current water demand. 


\subsection{Recommendations on Water Resources}

By the year 2075, the risk of the Lao Pao River stream flow being reduced to $0.15 \mathrm{~m}^{3}$ per second or less for at least 14 consecutive days is 1 in 8.8 years. This projection, based solely on the worst case climate change scenario (without changes in water demand), is well below the "acceptable risk" of 1 in 25 years. This projection alone, even without considering changes in water demand, implies the Government undertakes significant methods of adaptation to cope with future risk.

By the year 2075, the return period has become significantly shorter. This means that the re-occurrence of water shortages will be much more frequent. The original baseline information provided had determined that every 13 years the water would run out. With the changes associated with climate change alone being considered, the chance of running out of water increases to once every 9 years instead of once every 13 years.

Changing demand for water without considering climate change, makes a determination that water will be unavailable for consumption once every 8 years. By the year 2075, with climate change considered in addition to increased water demand, the city will run out of water once in every 11 years. Water demand change is more important in increasing the risk of running out of water, because the risks increase more with water demand increase (running out of water once in every 8 years) than they do with climate change alone (once in every 6 years) in the projected future changes.

Currently, there is 14 days' worth of storage available. With the current climate and current water demand, 6 additional days are required to establish a 25-day storage period, in line with the "acceptable risk" level determined by the Government. At 25 total days of storage capacity, the occurrence of running out of water will happen only once in every 25 years. This takes the return period and changes it from 1-in-13 to 1-in-25. These additional days of storage availability require $38,720 \mathrm{~m}^{3}$ of storage in addition to the already available $49,000 \mathrm{~m}^{3}$.

If we take the 14 day storage that is currently available, and consider only 7 days' worth of storage is available instead, thereby increasing the demand for water, we come up with a new scenario. At this point, it will still take 25 days' worth of storage to meet the 25 year return period. Therefore, it is determined that the return period will change from approximately 1 -in- 8 to 1 -in-25 by requiring an additional 18 days of storage capacity and $63,360 \mathrm{~m}^{3}$ of storage volume in this situation.

In the year 2075, considering increased demand in addition to climate changes, an additional 24 days' worth of storage will be required beyond the 7 days needed currently with increased demand. The return period will change from approximately 1-in-6 to 1-in-25 to meet the "acceptable risk" determined by the government of the 25 year period in which the potential to run out of water eventually arises. This additional time that will be necessary to store the water will require an additional $84,480 \mathrm{~m}^{3}$ of storage in the tanks.

When considering the future water demands and how they relate to climate change, we considered one option where the tourists who visit the island and the industry that sustains the tourists provide water for these tourists. In this way, it can be balanced where only the residents of the island are provided with water in our assessment. By taking the $220 \mathrm{~L}$ per capita that includes tourists and residents, and subtracting the $60 \mathrm{~L}$ per capita that includes only tourists, we come up with a figure that is $160 \mathrm{~L}$ per capita that includes only residents. When we take the ration of $220 \mathrm{~L} /$ day and the total storage needed for this consumption of $133,480 \mathrm{~m}^{3}$, and comparing it with the ratio of $60 \mathrm{~L} /$ day with an unknown storage capacity change, we came up with the ability to avoid storage of $36403.64 \mathrm{~m}^{3}$. This will save time and money when preparing water storage and stream flow capacity for the residents of Falulu.

\subsection{Coastal Erosion}

Coastal erosion poses a significant risk to communities around the Amilee area of the island of Falulu. In particular, the planned Lai Moana Beach Resort is faced with a great risk of erosion, considering its high cost. As previously observed by locals, shoreline erosion is already a significant risk in the area. However, sea level rise as a result of climate change will likely exacerbate this problem in the future. Figure 4(a) illustrates projected mean global sea level rise.

\subsection{Projection of Future Sea Level Rise}

Under a modest projection of the SRES A1B scenario, a mid-range global sea level rise shows approximately 31 centimeters by 2100 with the high-range showing a 56 centimetre rise. Figure 4(b) delineates the projected sea 


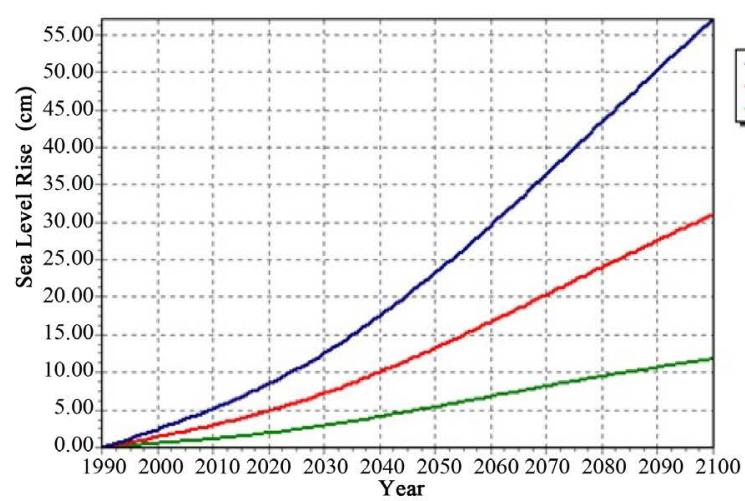

(a)

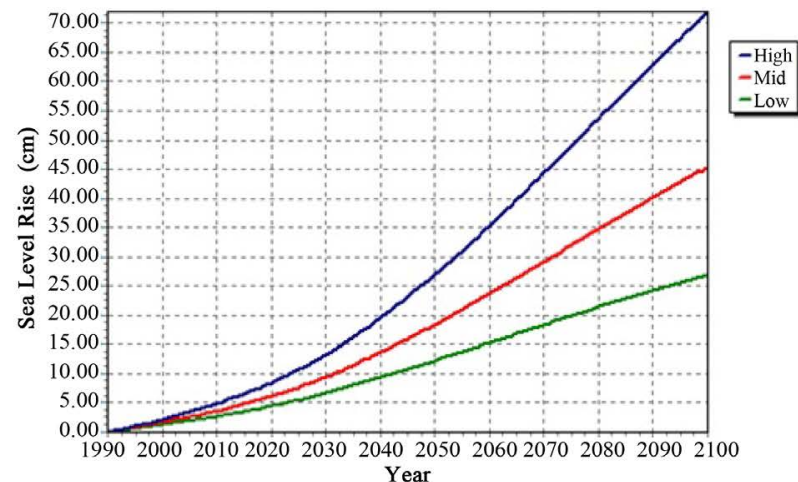

(b)

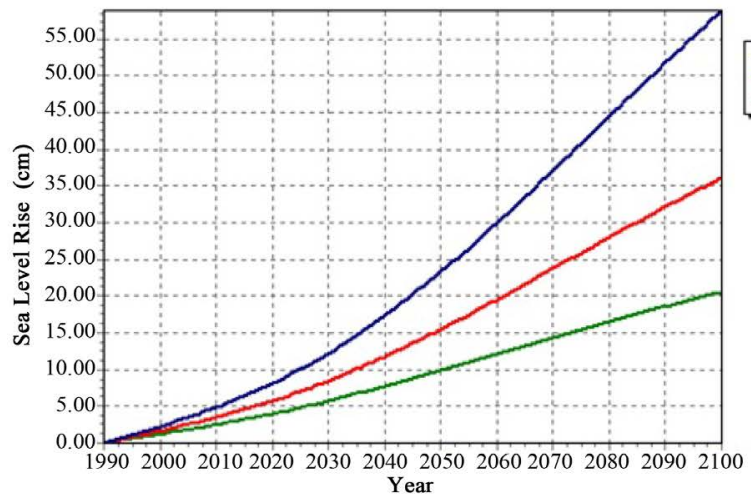

(c)

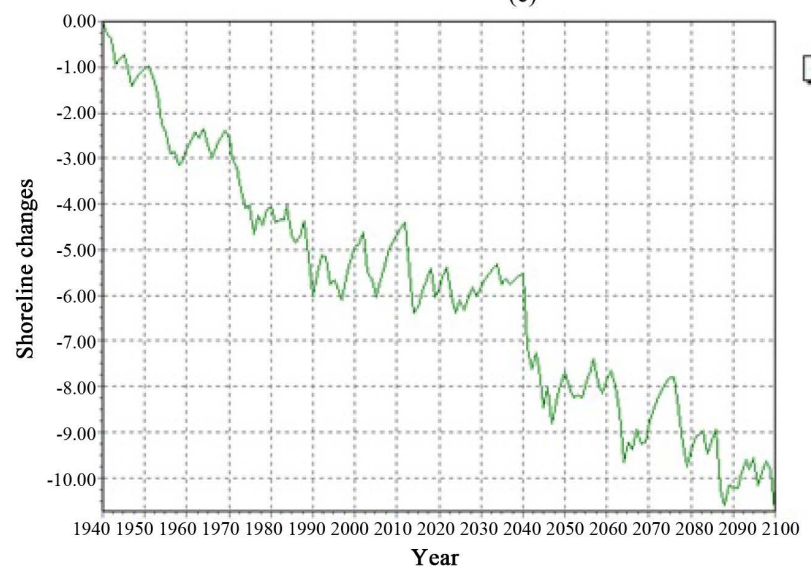

(d) 


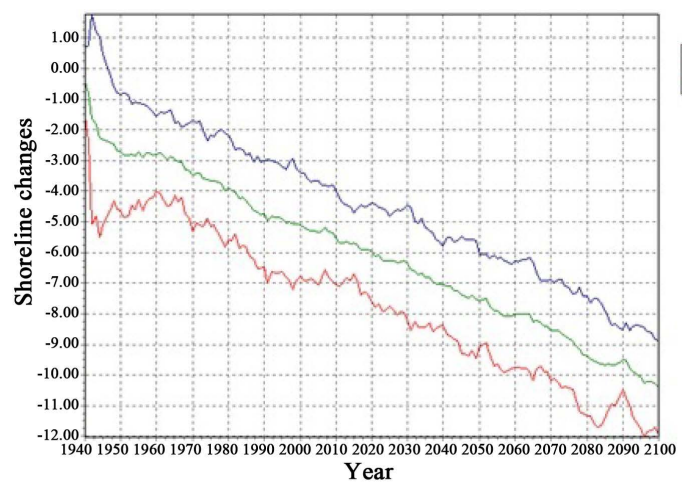

(e)

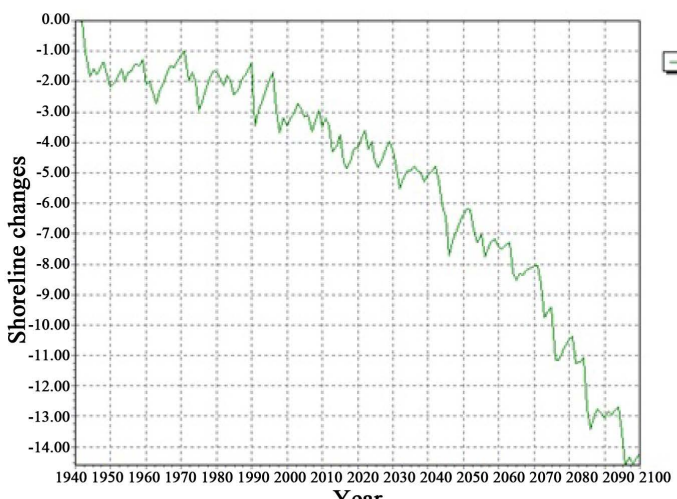

Year

(f)

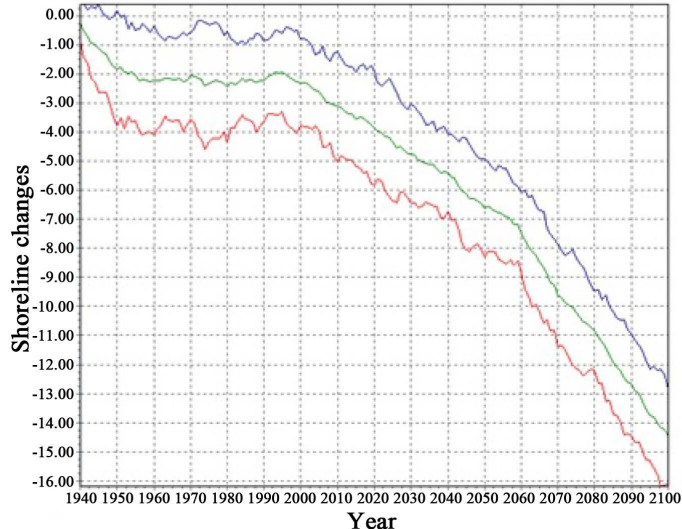

(g)

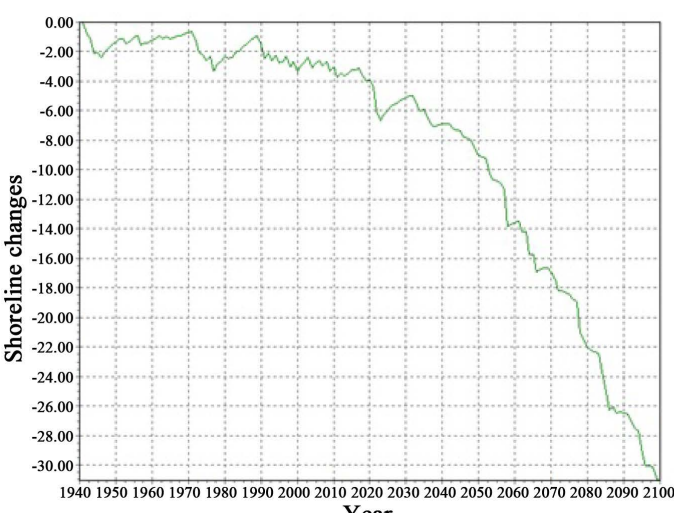

Year (h) 

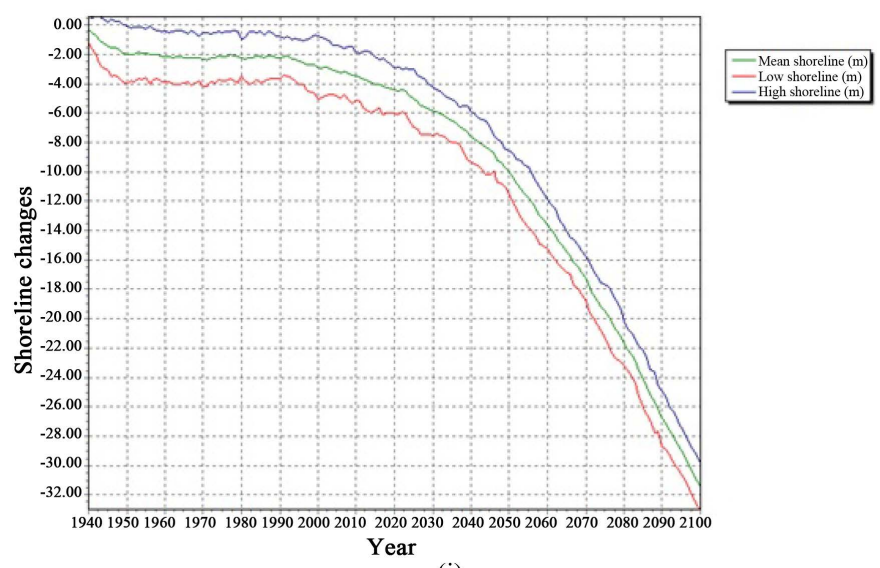

(i)

Figure 4. (a) Projections for global sea level rise using the HadCM3 model; (b) Graph showing site-specific projected sea level rise for the Amilee area using the HadCM3 model; (c) Graph showing site-specific projected sea level rise for the Amilee area using the CSIRO-MK2 model; (d) Graph showing trend in shoreline change (m) based on an observed sea level rise of 1.5 millimeters per year; (e) Graph showing mean, low and high shoreline change (m) based on an observed sea level rise of 1.5 millimeters per year using the Monte Carlo simulation with a confidence interval of 95\%; (f) Graph showing mid-range projections of shoreline change $(\mathrm{m})$ considering the impact of sea level rise from climate change (GCM pattern: CSIRO-MK2; SLR scenario: SRES A2; Climate sensitivity: mid; local observed sea-level trend: $1.5 \mathrm{~mm}$ ); (g) Graph showing mid-range projections of mean, low and high shoreline change $(\mathrm{m})$ considering the impact of sea level rise from climate change using the Monte Carlo simulation with a confidence interval of 95\% (GCM pattern: CSIRO-MK2; SLR (Sea Level Rise, see List of Abbreviations for further details) scenario: SRES A2 (Special Report on Emissions Scenarios, see List of Abbreviations for more detail); Climate sensitivity: mid; local observed sea-level trend: $1.5 \mathrm{~mm}$ ); (h) Graph showing high-range projections of shoreline change $(\mathrm{m})$ considering the impact of sea level rise from climate change (GCM pattern: HadCM3; SLR scenario: SRES A1FI (Special Report on Emissions Scenarios, see List of Abbreviations for more details); Climate sensitivity: high; local observed sea-level trend: $1.5 \mathrm{~mm}$ ); (i) Graph showing high-range projections of mean, low and high shoreline change (m) considering the impact of sea level rise from climate change using the Monte Carlo simulation with a confidence interval of 95\% (GCM pattern: HadCM3; SLR scenario: SRES A1FI; Climate sensitivity: high; local observed sea-level trend: $1.5 \mathrm{~mm}$ ).

level rise for the Amilee area of the Aysese Islands using the HadCM3 (developed by the United Kingdom Met Office Hadley Centre, see List of Abbreviations for further details) Model, while Figure 4(c) gives results of the same projection using instead the CISRO (developed by Australia's Commonwealth Scientific and Industrial Research Organisation, see List of Abbreviations for further details) Model.

The above two graphs display results from the HadCM3 and CSIRO-MK2 models, respectively. Mid-range projection is 15 centimeters by 2050 and 36 centimeters by 2100 . High-range sea level rise projected by 2050 is 27 centimeters and by 2100 is 71 centimeters. The results are shown in Table 3.

\subsection{Variations and Trends in Shoreline Position under Current Sea Level Trends}

According to existing data based on local knowledge an old photographs, over the last 50 years the shoreline has eroded by about $2-3$ meters, fluctuating between about $1-2$ every decade or so. Below is a graph showing a simulation of shoreline erosion under the observed sea level rise of 1.5 millimeters per year. Figure 4(d) gives a visual representation of how the shoreline is projected to change based on sea level rise effects.

The graph of the simulation above shows shoreline erosion to be approximately 0.5 meters per year or 2.5 meters every 50 years. This is entirely consistent with the observations based on local knowledge and old photographs. Inter-decadal fluctuations appear to be between 0.5 meters and 3 meters, also consistent with the local perceptions of 1 - 2 meters. Figure 4(e) shows high, low, and mean shoreline change based on the Monte Carlo simulation (a scenario generated by which uncertainty estimates of different sources are combined, see List of Abbreviations for further details).

Figure 4(e) shows the trend in shoreline erosion under a Monte Carlo simulation. By the year 2050, the lowrange projection of shoreline erosion (i.e. the greatest level of erosion) is approximately 9.3 meters. By the year 2100, the low-range projection (least erosion) is 12 meters. The results suggest a difference between low and high shorelines of 3.3 meters by 2050 and 3.1 meters by 2100 . Table 4 is articulating these results. 
Table 3. Table showing mid-range CSIRO-MK2 Global Circulation Models (GCM, see List of Abbreviations for further details) and high-range HadCM3 GCM projections for sea level rise in the Amilee area.

\begin{tabular}{ccc}
\hline Year & Mid-range values (with CSIRO-MK2 GCM results) & High-range values (with HadCM3 GCM results) \\
\hline 2050 & $15 \mathrm{~cm}$ & $27 \mathrm{~cm}$ \\
2100 & $36 \mathrm{~cm}$ & $71 \mathrm{~cm}$ \\
\hline
\end{tabular}

Table 4. High-range, mean, and low-range projections for shoreline change in 2050 and 2100.

\begin{tabular}{rccc}
\hline Year & $\begin{array}{c}\text { High-range projection of shoreline } \\
\text { (least erosion) }\end{array}$ & Mean projection of shoreline & $\begin{array}{c}\text { Low-range projection of shoreline } \\
\text { (greatest erosion) }\end{array}$ \\
\hline 2050 & $6.0 \mathrm{~m}$ & $7.5 \mathrm{~m}$ & $9.3 \mathrm{~m}$ \\
2100 & $8.9 \mathrm{~m}$ & $10.3 \mathrm{~m}$ & $12.0 \mathrm{~m}$ \\
\hline
\end{tabular}

\subsection{Trends in Shoreline Change under a Mid-Range Projection of Sea-Level Rise}

Figures 4(f)-(g) illustrate how the shoreline is projected to change using outputs of different scenarios.

\subsection{Trends in Shoreline Change under a High-Range Projection of Sea-Level Rise}

Figures 4(h)-(i) show high level projected shoreline changes from sea-level rise using multiple scenarios. Table 5 gives this data in verbal form from all scenarios used.

\subsection{Recommendations on Coastal Erosion}

Based on the analysis above, it is advised that the location of the Lai Moana Beach Resort be further from the shoreline. Under modest projections, the shoreline will be reduced by 6.5 meters by the year 2050 and by 14.3 meters by 2100. However, considering the greatest extent of erosion under high-range projections, the shoreline will be reduced by 10 meters by 2050 and by 31.2 meters by 2100 .

Given these figures, it is highly recommended that the buildings, infrastructure and facilities of the Lai Moana Beach Resort be sited at a minimum of 32 meters from the current shoreline in order to safely prevent inundation and be unaffected by coastal erosion until at least the year 2100 .

\subsection{Tropical Cyclones and Storm Surge Flooding}

The following is an analysis that addresses the issues of severe tropical cyclones and coastal flooding, especially with relevance to the vulnerable village of Smilart. This assessment will provide direction and recommendations on how to adapt to climate change in the most viable manner. We begin by looking at projected flood events between now and 2050, and the chance that they will occur every 25 years, and the chance that they will occur every 50 years. Figure 5 gives a visual representation of projected water inundation frequency events at different times and intensity of scenario.

In Figure 5, the differences are shown between water inundation frequency events. The two frequencies that are focused upon are the chance that the land will be inundated with water once every 25 years and once every 50 years. Once the chance is examined that this will happen under current circumstances, then to the right, conditions are examined in 2050, projecting changes with different intensities. The frequencies remain the same; however, mid-range and high-range scenarios for climate change and intensity of cyclones are examined in the middle and right-hand columns, respectively.

It is clearly illustrated how the storm intensities increase by visual representation of water level inundation, as well as by the numbers at the bottom of each map. These numbers represent the number of cells (also considered as the amount of land coverage) affected by the cyclone events in each situation. Table 6 gives a written description of the options given to meet future projections for storm surges in tropical cyclones, as well as the level of influence each option will make upon individual criteria, given as low, medium and high levels of impact.

In the above matrix, we offer a look to the options for adaptation, and their impacts on objective criteria. In the first criteria option, economic efficiency is determined for each option of adaptation. Further details on 
Table 5. Mean shoreline for mid-range projections (GCM pattern: CSIRO-MK2; SLR scenario: SRES A2; Climate sensitivity: mid; local observed sea-level trend: $1.5 \mathrm{~mm}$ ) and low shoreline (greatest erosion) for high range projections (GCM pattern: HadCM3; SLR scenario: SRES A1FI; Climate sensitivity: high; local observed sea-level trend: $1.5 \mathrm{~mm}$ ).

\begin{tabular}{ccc}
\hline Year & Mean shoreline for mid-range projections & Low shoreline (greatest erosion) for high-range projections \\
\hline 2050 & $6.5 \mathrm{~m}$ & $10.0 \mathrm{~m}$ \\
2100 & $14.3 \mathrm{~m}$ & $31.2 \mathrm{~m}$ \\
\hline
\end{tabular}

Table 6. Criteria considered in decision-making process.

\begin{tabular}{cccccc}
\hline & \multicolumn{4}{c}{ MULTI-OBJECTIVE CRITERIA } \\
\hline OPTION & $\begin{array}{c}\text { Economic } \\
\text { efficiency }\end{array}$ & $\begin{array}{c}\text { Environment } \\
\text { suitability }\end{array}$ & $\begin{array}{c}\text { Distributional } \\
\text { fairness }\end{array}$ & $\begin{array}{c}\text { Political } \\
\text { acceptability }\end{array}$ & $\begin{array}{c}\text { Development } \\
\text { promotion }\end{array}$ \\
\hline Raise floor heights & High & High & High & High & High \\
Sea-wall & Low & Low & Low & High & Low \\
Combination & Low & Medium & Low & High & Medium \\
\hline
\end{tabular}

\section{Present Climate}

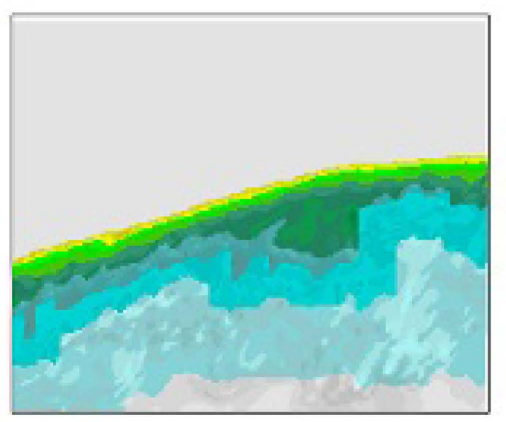

14871

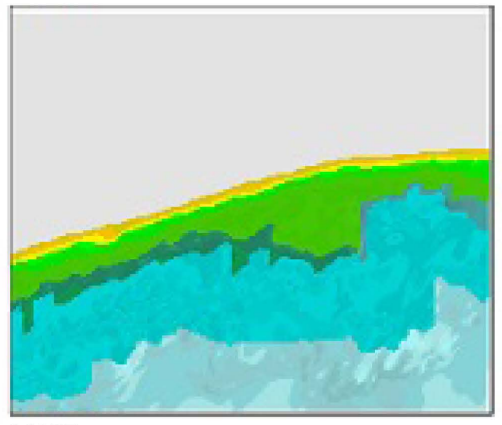

16887
2050 (mid scenario)

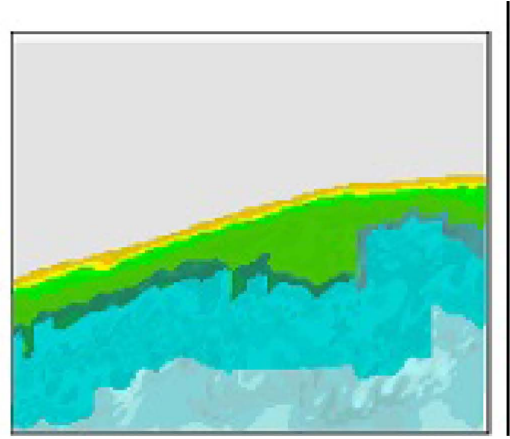

16890

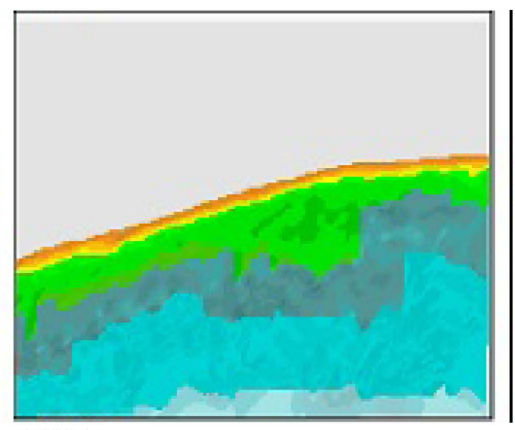

17004
2050 (high scenario)

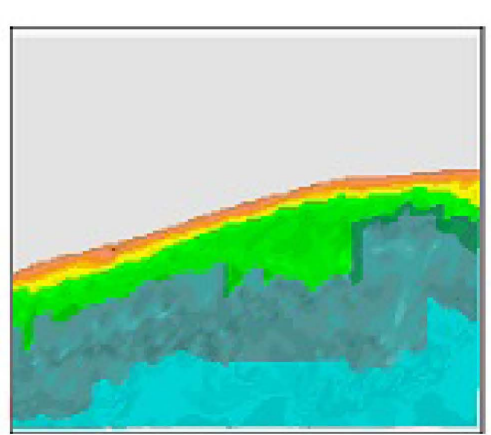

17036

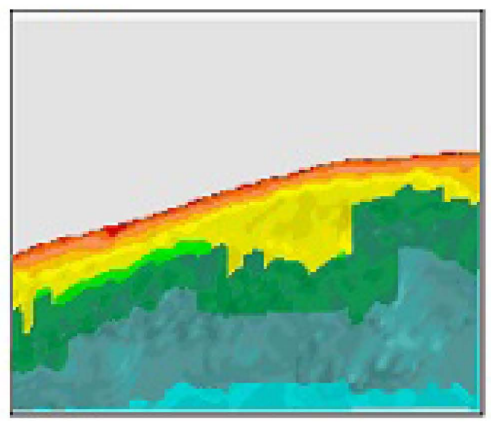

17054

\begin{tabular}{|c|c|}
\hline $0-1$ & $7-8$ \\
\hline $1-2$ & $8-9$ \\
\hline $2-3$ & $9-10$ \\
\hline $3-4$ & $10-11$ \\
\hline $4-5$ & $11-12$ \\
\hline $5-6$ & $12-13$ \\
\hline $6-7$ & $13-14$ \\
\hline
\end{tabular}

Figure 5. Indicators of impact: map showing inundation and number of cells inundated.

economic assessment can be found in Table 7.

Environmental suitability of each option was concluded from a process of consideration for the current coastal 
Table 7. Options of economic evaluations important for the government to consider.

\begin{tabular}{|c|c|c|c|c|c|}
\hline \multirow[b]{2}{*}{ OPTIONS } & \multicolumn{5}{|c|}{ ECONOMIC EVALUATIONS } \\
\hline & $\begin{array}{l}25 \text { yr. return } \\
\text { Floor Raising }\end{array}$ & $\begin{array}{l}50 \text { yr. return Floor } \\
\text { Raising }\end{array}$ & $\begin{array}{l}25 \text { yr. return } \\
\text { (5 m additional) } \\
\text { Sea-wall Raise }\end{array}$ & $\begin{array}{l}50 \text { yr. return } \\
\text { (9 m additional) } \\
\text { Sea-wall Raise }\end{array}$ & $\begin{array}{l}\text { Combination of the } \\
\text { two options }\end{array}$ \\
\hline Total benefits & 20.283 & 20.579 & 19.877 & 20.057 & 35.442 \\
\hline Total costs & 8.775 & 10.377 & 45.000 & 81.000 & 52.190 \\
\hline $\begin{array}{c}\text { Net benefits } \\
\text { (benefits minus costs) }\end{array}$ & 11.508 & 10.202 & -25.123 & -60.943 & -16.748 \\
\hline $\begin{array}{l}\text { Benefit-cost ration } \\
\text { (benefits/costs) }\end{array}$ & 2.311 & 1.983 & 0.442 & 0.248 & 0.679 \\
\hline $\begin{array}{l}\text { Incremental Costs } \\
\text { (GEF Payment) }\end{array}$ & 4.745 & 4.981 & 0.000 & 0.000 & 3.521 \\
\hline $\begin{array}{l}\text { Cost less Incremental } \\
\text { Costs (Cost after } \\
\text { GEF Payment) }\end{array}$ & 4.030 & 5.486 & 45.000 & 81.000 & 48.669 \\
\hline
\end{tabular}

ecosystem and the viability of each option. Raising floor heights does not diminish the natural ebb and flow of tide cycles as a sea-wall has the ability to do, while a combination of the two offers a small gesture towards environmental sustainability. This occurs in the way of allowing sea-wall to diminish coastal ecosystems while allowing raised floor heights which do not affect coastal ecosystems, to also be used.

Distributional fairness is a consideration of who pays the costs and what is considered fair in the payment of such cost. Raising floor heights is the most economical option for whoever will pay the costs, while sea-wall construction and a combination of the two are high costs with little benefit, as will be noted in Table 7 and its description.

Political acceptability bears in mind what interests are part of the process of building sea-walls, constructing homes with raise floors, as well as a combination of the two. In this area, any perspective is possible to see the project in a light that may be politically beneficial, so political acceptability is able to be high for all 3 options.

Promotion of development is carefully thought out in the way that every nation continues to work towards economic development. It is important that all three options for development consider the current industries that generate income for the nation and the region. Raising floor heights will not interfere with agriculture, fishing or tourism-the three main sources of revenue. Building a sea-wall will negatively affect tourism, and possibly lead to degradation of the aquatic ecosystem near the coast, which could potentially influence the fishing industry as well. A combination of the two may lead to a small diminishment in tourism, fishing (for the same reasons given above) and agriculture if the fields become flooded due to the fact that water comes over the sea-wall at any time and floods and/or adds salinity to the soil.

\subsection{Recommendations on Tropical Cyclone and Storm Surge Flooding}

The bottom line is the most important factor for many decisions that are made, politically, economically, and developmentally. The sea-wall option is the most expensive, and pertains to adding additional $5 \mathrm{~m}$ to the existing $4 \mathrm{~m}$ structure to meet the $25 \mathrm{yr}$ occurrence of a cyclone storm surge, while the 50 year return period has an additional $9 \mathrm{~m}$ added to the existing height to meet that expected cyclone storm surge event. In this consideration of the importance of the viability of these adaptations, we are making a strong recommendation for the 50 year return floor raising option, without the building of a sea-wall. As you can see above, any consideration of a sea-wall drives cost to extremes. In considering the 2 reasonable economic options of floor-raising, the second one (50 yr return) will add barely any cost to the amount that is requested from the Global Environment Facility (GEF), and only $1.456 \mathrm{M}$ to the cost of the Government. Although there is a less expensive option (25 yr return for floor-raising), this provides only half of the protection that is possible, and leaves the population of the region, including the Prime Minister of the Aysese Islands, and his family at risk for floods and the devastation that follows. The 50 year floor raising option gives the most environmental sustainability, the most protection to the residents of the region, and offers much less of a recurrence of floods and storm surges to local residents and businesses, including tourism and agriculture. It is 14 times less expensive than the highest cost option, and it is 
also ethically the right decision.

In closing, it is recommended to the Government request funding from the GEF because they are an institution that is centered on the Global Environment. The only funding that is requested of them is the difference of increase that comes into each scenario in considering global climate change as a factor. If the scenarios for modifications were prepared and carried through without global climate change considerations, then the entire region's lives and economic stabilities are at risk. It is imperative that global climate change continue to be considered in the efforts of adapting to these changes, because extremes in precipitation are likely to increase in many regions of the South Pacific Ocean area [1]. Pacific Island countries are ranked among the top in the world in vulnerability to natural disasters [8]. From 1950 to 2004, extreme disasters such as cyclones and tsunamis attributable to climate change accounted for 65 percent of the total economic impact from catastrophes on the regions' economies [1] [8]. It is therefore imperative that we remain vigilant in addressing climate change as a component of the decision-making process. The GEF must be urged to provide available funding they have for addressing global environmental issues to this project. This is a major global climate change concern that affects local ecosystems and their environments, and fits simply into the guidelines presented for requesting funding from this institution.

\section{Conclusions}

In summary, the conclusions that can be drawn are simple examinations of prior detailed recommendations for changes for continued improvements to the growth and development of The Republic of the Aysese Islands. In the first section, we determined the factors that were relevant to the report in the entire scope of the assessment. The end product represented a need to address particular factors that are important to consider. The conclusions in the first section came to three main factors to address: water resources, the coastal zone, and, finally, tropical cyclones and storm surge events. This section also addresses climate change and the validity of its relevance to the current region in relation to the rest of the globe. In findings from the IPCC, it is clearly and strongly determined that climate is indeed changing, and concerns to this effect that must be included in all assessments of adaptation to any future risks to the region.

In the section on Water Resources, the Government of the Aysese Islands (GAI) asked us to address the issues of water supply and climate change as it pertained to development of the region. After assessment of the water availability and storage, it has been initially determined that the current water supply is at an unacceptable level of the amount of storage available as well as the return period for low flow events in the river used for water catchment and supply. It is highly recommended that in addition to education of residents as to how to keep water safe and free from bacterial contaminants, the water storage be increased to make enough clean water available to all residents and tourists. The costs of such action will be offset by providing education to the residents to allow them to take ownership of making their own clean water. The infrastructure required to provide all of the required amounts of water can also be worked by residents, creating jobs in addition to improving knowledge. Clean water supply for all is essential to every other activity in the country.

In coastal erosion report, the focus was upon the Government of the Aysese Islands (GAI) request to address the issues of sea-level rise and shoreline changes as they pertained to future tourism developments. After careful analysis, the recommendation is correct and proper to state a need to move back the building of the Lai Mauna Resort at least $32 \mathrm{~m}$. This will prevent erosion of the coastline to the start of the property line of the proposed resort. After all considerations of possible erosion scenarios, we have evaluated this to be the best option. It is also important to remember that tourists visiting a resort want and usually expect a beach area. Without one, the investment returns on the property and the resort will be minimized. If it is possible to move the start of the building back further than $32 \mathrm{~m}$ from the shoreline, this will be our best recommendation.

The tropical cyclones and storm surge flooding section was composed for the GAI to address the issues that they bring, especially with relevance to the vulnerable village of Smilart. After thoughtful analysis of many detailed models, our determinations have been found to show the best cost/benefit ratio for the highest level of protection to be selected. There is a matrix provided to ascertain the reasoning behind the selection. Ultimately, it is recommended that GAI choose the 50-year return period selection for raising the floor of all building to prevent cyclone and flood damages. This will also prevent loss of life and major economic downfalls over the next 50 years at least.

It is imperative that future assessments be conducted on at least a decadal scale, potentially every 5 years even, to be sure that adaptations are working and up to par on what is acceptable in the risk scenarios. 


\section{Acknowledgements}

We wish to thank Dr. Richard Warrick, of CLIM Systems and University of the Sunshine Coast for providing us with a set of tools that have been invaluable in producing this information. We also wish to thank our funding agencies USDA-NIFA for both climate change education grants and NSF MADE-CLEAR Program for the opportunity to have this experience and be able to produce information based on what we have experienced. Special thanks to the Climate Change Adaptation group members: Alexis Jackson, Kelly Pelz-Butler, Pamela Stampul, Sydney Kouri and Walter Matthews.

\section{References}

[1] Solomon, S., Qin, D., Manning, M., Alley, R.B., Berntsen, T., Bindoff, N.L., Chen, Z., Chidthaisong, A., Gregory, J.M., Hegerl, G.C., Heimann, M., Hewitson, B., Hoskins, B.J., Joos, F., Jouzel, J., Kattsov, V., Lohmann, U., Matsuno, T., Molina, M., Nicholls, N., Overpeck, J., Raga, G., Ramaswamy, V., Ren, J., Rusticucci, M., Somerville, R., Stocker, T.F., Whetton, P., Wood, R.A. and Wratt, D. (2007) Technical Summary. In: Solomon, S., Qin, D., Manning, M., Chen, Z., Marquis, M., Averyt, K.B., Tignor, M. and Miller, H.L., Eds., Climate Change 2007: The Physical Science Basis, Contribution of Working Group I to the Fourth Assessment Report of the Intergovernmental Panel on Climate Change, Cambridge University Press, Cambridge, United Kingdom and New York, NY, USA.

[2] Field, C., Barros, V. and Mastrandrea, M. (2014) Technical Summary: Climate Change 2014: Impacts, Adaptation, and Vulnerability. IPCC WGII AR5 Technical Summary, 76.

http://ipcc-wg2.gov/AR5/images/uploads/WGIIAR5-TS_FGDall.pdf

[3] Global Issues (2013) Coral Reefs: Global Threats to Coral Reefs. Climate Change Causing Global Mass Coral Bleaching. http://www.globalissues.org/article/173/coral-reefs\#

[4] Hossain, M.A. (2011) Global Warming Induced Sea Level Rise on Soil, Land and Crop Production Loss in Bangladesh. Journal of Agricultural Science and Technology, 1, 266.

http://connection.ebscohost.com/c/articles/86164944/global-warming-induced-sea-level-rise-soil-land-crop-productionloss-bangladesh

[5] IRIN (2014) GLOBAL: Cholera, Climate Change and El Nino. IRIN Humanitarian News and Analysis. Report: 86487. http://www.irinnews.org/report/86487/global-cholera-climate-change-and-el-ni\%C3\%B10

[6] Traerup, S.L.M., Ortiz, R.A. and Markandya, A. (2010) The Health Impacts of Climate Change: A Study of Cholera in Tanzania. Basque Centre for Climate Change. Klima Aldaketa Ikergai. BC3 Working Paper Series 2010-01, 27. http://www.bc3research.org/working_papers/view.html

[7] Keener, V.W., Marra, J.J., Finucane, M.L., Spooner, D. and Smith, M.H. (2012) Climate Change and Pacific Islands: Indicators and Impacts. Executive Summary of the 2012 Pacific Islands Regional Climate Assessment (PIRCA), 7. www.EastWestCenter.org/PIRCA http://www.cakex.org/sites/default/files/documents/Exec-Summary-PIRCA-FINAL2.pdf

[8] Bettencourt, S., Croad, R., Freeman, P., Hay, J., Jones, R., King, P., Lal, P., Mearns, J., Miller, G., Pswarayi-Riddihough, I., Simpson, A., Teuatabo, N., Trotz, U. and Van Aalst, M. (2006) Not If but When: Adapting to Natural Hazards in the Pacific Islands Region, a Policy Note. World Bank. East Asia and Pacific Region. Pacific Islands Country Management Unit.

[9] Griffiths, G.M., Salinger, M.J. and Leleu, I. (2003) Trends in Extreme Daily Rainfall across the South Pacific and Relationship to the South Pacific Convergence Zone. International Journal of Climatology, 23, 847-869. http://onlinelibrary.wiley.com/doi/10.1002/joc.923/pdf http://dx.doi.org/10.1002/joc.923

[10] IPCC (2014) Working Group I: The Scientific Basis. The Projections of the Earth’s Future Climate. The IPCC Special Report on Emissions Scenarios (SRES). http://www.ipcc.ch/ipccreports/tar/wg1/029.htm

[11] Nicholls, R.J., Hoozemans, F.M.J. and Marchand, M. (1999) Increasing Flood Risk and Wetland Losses Due to Global Sea-Level Rise: Regional and Global Analyses. Global Environmental Change, 9, S69-S87. http://dx.doi.org/10.1016/S0959-3780(99)00019-9 


\section{List of Abbreviations}

A1B - The A1 group of scenarios is recognized by:

- Rapid economic growth.

- A global population that reaches 9 billion in 2050 and then gradually declines.

- The quick spread of new and efficient technologies.

- A convergent world-income and way of life converge between regions. Extensive social and cultural interactions worldwide.

- A1B specifically refers to a balanced emphasis on all energy sources.

CGCM2-This scenario was developed by the Meteorological Research Institute in Japan. This scenario is generated using all available scenarios to produce a more balanced perspective that will finalize numbers that are closest to actual in a projection.

HADCM3-This scenario was created by the United Kingdom Met Office, Hadley Center. It assumes the same integration of all available scenarios given by the IPCC, but without using a scenario that generates four times the potential projected levels of change.

CSIRO-MK2_Climate Change Scenario generated by Australia's Commonwealth Scientific and Industrial Research Organisation. This scenario integrates the A1, A2, B1 and B2 scenarios to produce future projections.

GCM-General Circulation Models that representing physical processes in the atmosphere, ocean, cryosphere and land surface. They are the most advanced tools currently available for simulating the response of the global climate system to increasing greenhouse gas concentrations.

Monte Carlo Simulation-based on a broad class of computational algorithms that rely on repeated random sampling to obtain numerical results by running simulations many times over in order to calculate those same probabilities. This is intended to use multiple scenarios to generate the most accurate one possible.

SLR - Sea Level Rise scenarios. These are given and produced with four levels of expected outcomes: Highest, Intermediate-High, Intermediate-Low, and Lowest levels of SLR.

A1F1 - A member of the A1 group of scenarios detailed above in this list. The difference in A1F1 is that there is an emphasis on fossil-fuels (Fossil Intensive) usage.

A2 - The A2 scenarios are of a more divided world. The A2 family of scenarios is characterized by:

- A world of independently operating, self-reliant nations.

- Continuously increasing population.

Regionally oriented economic development. 
Scientific Research Publishing (SCIRP) is one of the largest Open Access journal publishers. It is currently publishing more than 200 open access, online, peer-reviewed journals covering a wide range of academic disciplines. SCIRP serves the worldwide academic communities and contributes to the progress and application of science with its publication.

Other selected journals from SCIRP are listed as below. Submit your manuscript to us via either submit@scirp.org or Online Submission Portal.
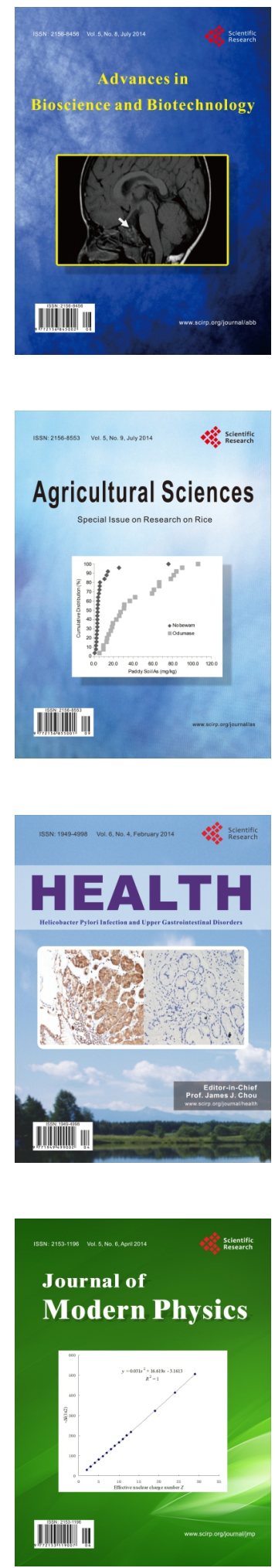
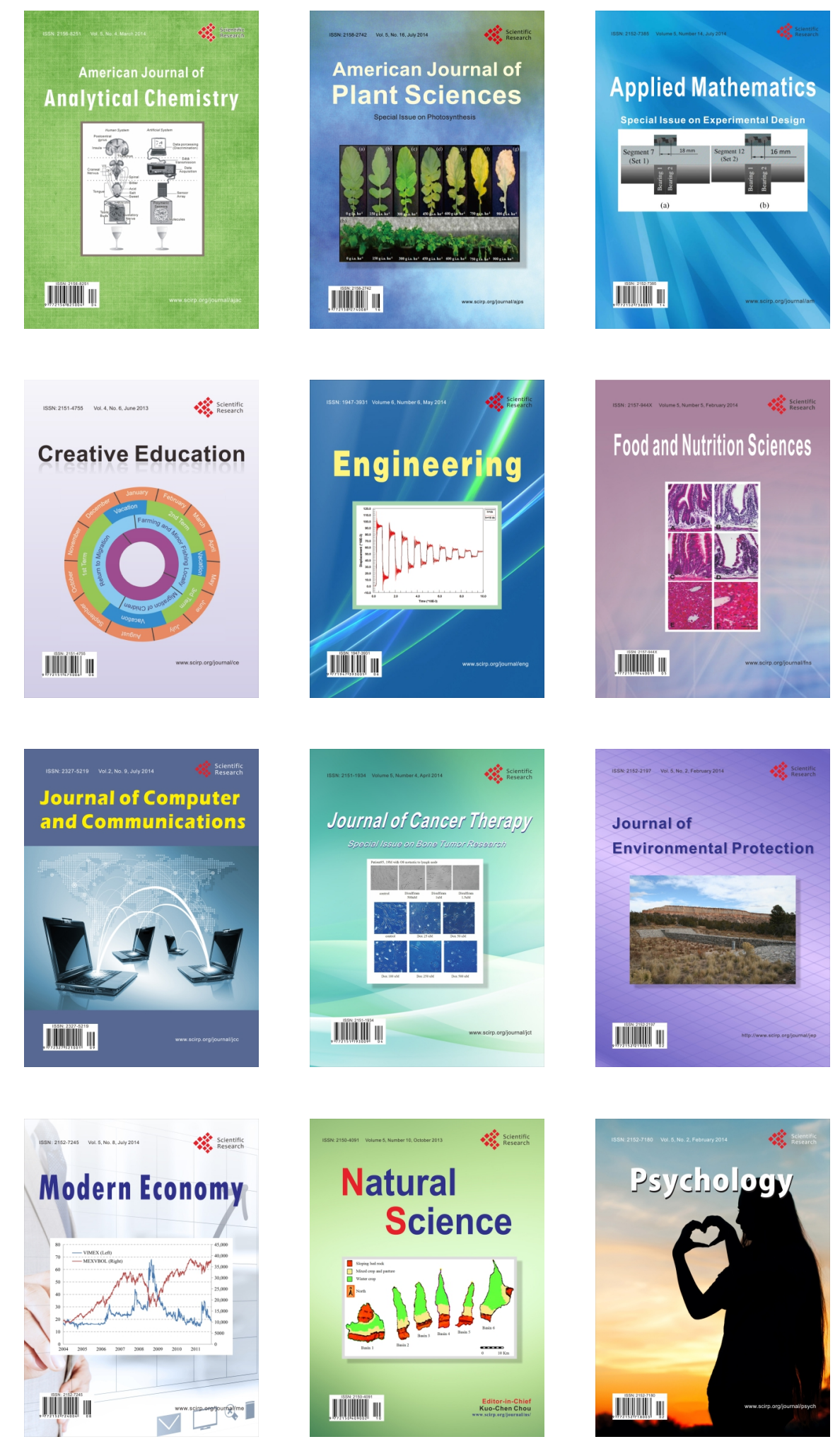